\title{
Reflexiones sobre las escrituras de la historia en El Salvador
}

\author{
Sajid Alfredo Herrera Mena \\ Universidad Centroamericana José Simeón Cañas
}

La etapa de la posguerra experimentó un importante suceso dentro del mundo académico, fundamentalmente para el avance de las Ciencias Sociales en el país: el inicio de la carrera de Historia en la Universidad de El Salvador, en el año de 2001. La Escuela de Historia de la Universidad de El Salvador ha impulsado el estudio del pasado con nuevos enfoques y perspectivas desde sus aulas o a través de conferencias, publicaciones y coordinando la organización de congresos nacionales y centroamericanos. Hasta diciembre de 2013, la escuela había graduado a 18 licenciados y egresado a nueve estudiantes.

El historiador costarricense, Víctor Hugo Acuña, invitado por aquella escuela a dictar la conferencia inaugural de los cursos universitarios de 2002, sugirió algunas líneas de trabajo para la naciente comunidad académica de historiadores. Acuña subrayó la importancia del estudio crítico del pasado; la colaboración entre la academia y los historiadores locales, genealogistas y anticuarios; el reconocimiento a las diferencias, así como la responsabilidad del historiador con el estudio de los períodos recientes en Centroamérica, marcados por conflictos armados, masacres y procesos de paz. De esta forma comenzaba, entonces, un periplo que en los últimos años ha arrojado interesantes frutos en un área de investigación dentro de las Ciencias Sociales.

Pero, una de las preguntas que muchas veces nos hemos hecho es ¿por qué llegamos tarde a la profesionalización de los estudios históricos en el país? Como sabemos, en El Salvador no es que se haya carecido de "ciertas escrituras de la historia", pero la no profesionalización del oficio del historiador tuvo un período más prolongado en comparación con los países vecinos. De hecho, cuando en las décadas de 1950 y 1960 se creaban departamentos de Historia en las universidades públicas centroamericanas, en El Salvador no pasó de ser un efímero proyecto de enseñanza y 
un estupendo laboratorio de análisis que terminó fracasando (Herrera Mena, 2014).

El historiador Knut Walter ha sostenido que, a diferencia de sus vecinos centroamericanos, el país se vio afectado durante el siglo XX para avanzar en la profesionalización de los estudios históricos por un limitado apoyo de las instituciones públicas, así como el difícil acceso a las fuentes documentales que son la materia prima de este campo de conocimiento. En ese sentido, la signatura de Historia de El Salvador no fue -ni sigue siendo-, o lo fue de manera intermitente, un componente de los planes curriculares de educación básica y media. Cuando fue impartida, los métodos pedagógicos no fueron los más felices, forzando a niños y jóvenes a memorizar datos biográficos, fechas y lugares a los cuales no les encontraban sentido y sin inducirlos al análisis e interpretación crítica. Asimismo, y a diferencia de otros países en América Latina, los 50 años de gobiernos militares no supieron o no pudieron explotar el recurso del pasado en función de sus propios proyectos políticoideológicos; probablemente, nos dice Walter (2005), porque "el ejército (salvadoreño) no había ganado ninguna guerra desde que participó, junto con otros de Centroamérica, en la campaña contra William Walker en 1856" (p. 20).

No obstante, y más allá de las razones que pudieran darse del atraso, los que investigamos en este campo del conocimiento necesitamos plantearnos ciertos aspectos que nos permitan prever algunos escenarios y retos futuros para la "escritura de la historia" en El Salvador.

Hace 13 años Héctor Pérez Brignoli, un historiador argentinocostarricense, proponía, en el contexto del Primer Encuentro de Historia de El Salvador, diez preguntas sobre diez temas que a su juicio eran relevantes y que necesitaban una mayor profundización: la densidad poblacional, el liderazgo salvadoreño en el tema unionista en la región, la presencia de los militares en la vida política, la aparición tardía de los partidos políticos, la población indígena, las élites económicas, la rebelión de 1932, la difícil consolidación de la democracia representativa, la incapacidad de los sectores empresariales por generar condiciones laborales dignas y la laboriosidad salvadoreña, entendida en su encrucijada como estereotipo o realidad.

La agenda de investigación planteada por Pérez Brignoli sigue teniendo mucha vigencia porque las problemáticas sugeridas todavía no han sido abordadas lo suficiente $y$, por lo mismo, requieren de un esfuerzo colectivo de varios años de trabajo en archivos locales e internacionales; requieren del distanciamiento crítico-metodológico de ciertas experiencias que 
todavía están palpitantes, para no contaminar el análisis, así como del diálogo multidisciplinario y bajo renovados marcos teóricos.

No obstante, podemos añadir otras líneas de investigación que, quizá, puedan enriquecer y complejizar a las de Pérez Brignoli. En primer lugar, y a pesar de ser muy novel la profesionalización de la historia en el país, no objeta para que no se hagan esfuerzos por reflexionar sobre la tradición historiográfica salvadoreña, acumulada en los últimos dos siglos y elaborada fundamentalmente por juristas y literatos. Hasta hace unos pocos años la reflexión sobre el relato historiográfico generó un creciente interés en los círculos académicos salvadoreños. Si bien hemos estado familiarizados con las diversas versiones del pasado, elaboradas desde tradiciones diversas -incluso antagónicas-, poco interés merecieron los modos de cómo se habían elaborado la narrativa, las metodologías, los marcos teóricos o el tipo de fuente utilizada. Estos son aspectos de relevancia capital, si se considera que su discusión forja excelentes bases para la generación de estudios sobre nuestro pasado con el rigor que exigen las Ciencias Sociales.

El relato historiográfico salvadoreño, elaborado en el siglo XX, fue en gran parte heredero de una versión maniquea decimonónica y quedó preso en la creación de un panteón de próceres y mártires, tan normal en todo proceso de construcción nacional; pero el problema es que terminó marginando a otros sectores y actores, así como a otros lenguajes y prácticas que cargaron el estigma de la traición, de constituirse en el enemigo de la patria, de formar la plebe tumultuaria o de no estar a favor de un proceso revolucionario. Así, por ejemplo, la tradición liberal señaló como traidores de la patria a aquellos pueblos que decidieron anexarse al Imperio mexicano, cuando ni siquiera existía en ese momento la República de El Salvador; o por otro lado, la tradición marxista estigmatizó a aquellos subalternos (indígenas, campesinos, artesanos) que no se vincularon a los procesos revolucionarios, calificando sus luchas como irrelevantes o movidas por su falsa conciencia.

El reto se nos presenta en continuar revisando críticamente las distintas tradiciones historiográficas salvadoreñas, tratando de entender sus interpretaciones sobre los textos, contextos y actores. De esa forma, tendríamos mayores y mejores argumentos para distanciarnos de aqueIlas percepciones que obstaculizan nuestra comprensión del pasado o, por el contrario, de aproximarnos a él a través de las percepciones que los contemporáneos dieron a la realidad que les correspondió vivir. Sin lugar a dudas, la coyuntura salvadoreña de posguerra ha favorecido esta línea de investigación 
y análisis, que se ha caracterizado por ser más inclusiva, alejada de prejuicios, desde la cual se ha querido enfrentar a una "historia única", como diría Gianni Vattimo (2003). Una "historia única" que ha buscado, desde la tradición que haya sido, a los vencedores (hombres, blancos y militares para la historia oficial; obreros concienciados y revolucionarios para la tradición marxista), condenando con ello al olvido o la marginación a otros sectores de la sociedad.

En segundo lugar, se debe apostar por sugerir, gestionar y apoyar la creación de mejores condiciones para la investigación. El laboratorio de los historiadores se encuentra en los archivos, en donde están resguardadas todo tipo de documentaciones: manuscritas, impresas, fotográficas, artísticas, entre otras. Pero asimismo, para muchos historiadores su laboratorio se encuentra en la calle, en la plaza, en las zonas rurales y urbanas. Ese es el campo de acción de la historia oral, que busca entender un pasado no tan lejano a través de la entrevista a sus sobrevivientes.

Sin embargo, este último laboratorio no podemos controlarlo mucho, no así el primero. Por tanto, se nos plantea el reto de apoyar toda iniciativa por fortalecer la red de archivos nacionales. Por fortuna, en los últimos cuatro años, con la Ley de Acceso a la
Información Pública, las instituciones estatales y autónomas han crecido en el convencimiento de mapear, ordenar y resguardar sus archivos. Ello permitirá en unos cuantos años contar con repositorios municipales y del gobierno central ordenados, clasificados y en buen estado para servir de materia prima a investigaciones en torno al funcionamiento de las instituciones públicas del país. Así, por ejemplo, podremos estudiar más a fondo aspectos como el funcionamiento judicial y carcelario, los proyectos de salubridad, urbanismo y de educación; la labor de las instituciones culturales y los años de bonanza o de turbulencia económica, entre muchos otros.

Con todo, los fondos de investigación no se limitan a los archivos públicos. Hoy sabemos que los archivos eclesiásticos y militares así como algunas bibliotecas privadas constituyen valiosos repositorios documentales sobre gran parte de nuestra historia. Sin embargo, el acceso a ellos está todavía restringido por múltiples razones que impiden el avance del conocimiento. No es el caso de los archivos de algunas instituciones no gubernamentales, que preservan documentación sobre la guerra civil de la década de 1980, y que han posibilitado en estos últimos años aproximaciones más interesantes a dicho suceso, más allá de lo que nos ha dicho la proliferación de los relatos autobiográficos. 
En tercer lugar, los historiadores deberíamos contribuir a la investigación multidisciplinaria de los grandes problemas que afectan a la sociedad salvadoreña; añadir la dimensión del pasado, la variable temporal, es lo que ha hecho falta en muchos de los planteamientos políticos, en los informes gubernamentales o de instancias internacionales instaladas en el país, sobre fenómenos como la violencia social, la migración o la crisis medioambiental. La novel profesionalización del quehacer historiográfico, el prejuicio de algunos sectores sobre ese quehacer que lo consideran como una mera crónica o el peso que sigue teniendo la denominada "historia oficial" han contribuido a que no sean involucrados los historiadores en las mesas donde se debaten académicamente aquellos $\mathrm{u}$ otros asuntos de interés nacional y regional.

Una manera de diluir este abismo es ciertamente demostrándolo con nuestros trabajos de investigación. Por ejemplo, algunos trabajos realizados en los años recientes sobre la violencia en la era colonial y en el siglo XIX han hecho ver cuán erradas eran las posturas que adjudicaban la raíz de los mismos a la etapa de posguerra, a los cincuenta años de regímenes militares $\mathrm{O}$, incluso, a la matanza de 1932. Dichos estudios han enfatizado que la violencia social es un constructo sociohistórico que ha sido una manera cómo los y las salvadoreñas han aprendido a resolver sus problemas a través de los tiempos y, que por lo mismo, sus soluciones van más allá de simples proyectos cosméticos o de corto plazo. Por ejemplo, la violencia en el siglo XIX no solamente se manifestó a través del trabajo coercitivo de muchos indígenas y ladinos en las haciendas, legitimado por los reglamentos contra la vagancia; no solo se manifestó a través de las continuas guerras al interior del país o en las que este participó regionalmente; también, y curiosamente, fue una estrategia de inclusión social; efectivamente, como lo vio Marta Irurozqui, estudiando el caso boliviano en el mismo siglo, se han podido observar estrategias similares de las élites salvadoreñas decimonónicas. La violencia fue, pues, un bautismo de ciudadanía republicana, es decir, la forma como se incorporaron a muchos indígenas y ladinos al proyecto de modernidad política a través de su apoyo militar a los bandos en contienda. La violencia, entonces, no fue signo de muerte sino de inclusión.

En cuarto lugar, no cabe duda que se presenta como un reto para los historiadores el estudio de una temática que para algunos es un delirio culturalista de las élites, pero que para otros es una dimensión insoluble del proyecto de país que somos o que pretendemos ser. Algunos ciudadanos lo plantean como el problema de la o las identidades; otros, como la 
recuperación de la memoria histórica, nacional o de las memorias locales. Lo cierto es que para los historiadores, al igual que para otros cientistas sociales, el pasado colectivo y las señas de sus identidades se convierten en un problema de investigación con una enorme riqueza y potencial, más allá de lo que ciertas tradiciones economicistas quieren hacernos creer. En efecto, estudiar estos hechos de manera problematizada no es caer en pseudos estudios por creer que se trata de meros reflejos de la realidad sociopolítica o, como creyeron muchos materialistas ingenuos, por creer que se trata de meros productos epifenoménicos de la base económica.

La o las memorias, entendidas como lo sostiene M. Hallbwachs, es una acción social, un recuerdo no solo individual, sino también colectivo de reconstrucción constante y que, de acuerdo a P. Nora, se va materializando en ciertos lugares ("Ios lugares de la memoria": museos, monumentos, sitios, etc.), en donde la sociedad recuerda constantemente a los suyos. La labor crítica, interpretativa y basada en la diversidad de fuentes permitirá a los historiadores entender y clasificar los distintos tipos de memoria construidas. Asimismo, advertir de los peligros de algunas que, con el propósito de presentarse como el relato que da legitimidad a la identidad del pueblo, como la narrativa que da cuenta de los orígenes de la Nación o como el discurso que establece la lucha entre el bien y el mal, no son más que otras construcciones a las que es preciso analizarlas en el contexto en el que fueron elaboradas, sus motivaciones y estructuras lógicas, para dar cuenta de sus propósitos.

La posguerra salvadoreña ha permitido la creación de una "memoria pública" en donde vienen rivalizando por su hegemonía la "memoria oficial" y la "memoria popular". ${ }^{1}$ Ambas han logrado forjar procesos de identidad, a través de sus propios mitos, símbolos y rituales, aglutinando, incluso, lealtades políticas. Ambas, también, han sido creaciones y re-creaciones a partir de sedimentos o recuerdos de pasados heroicos para unos, y traumáticos para otros, los cuales proporcionan legitimidad a la "sociedad política". Si bien, previo a la guerra, parecía que el "exceso" u "obsesión" por la memoria era una característica de los regímenes políticos del país, la cual estuvo anclada en los héroes independentistas y liberales decimonónicos, en la era de la posguerra la izquierda no se quedó de brazos cruzados. Este sector ha monumentalizado a sus mártires desde la matanza de 1932 hasta la década de 1980. Compitiendo con el panteón oficial, el panteón construido por la izquierda ha venido a enriquecer la "memoria pública", no sin mayores conflictos: en la actualidad plantean la necesidad de construir 
nuevos mitos o nuevos referentes, probablemente con la misma fuerza como los que movieron a muchos a participar en el conflicto armado en la década de $1980 .^{2}$

Gracias a estos procesos recientes de construcción de una "memoria pública", la "historia única", es decir, el relato soberano que sobredimensionó a un actor -sea cual fuere- en detrimento de otros, ya no tiene legitimidad. Jacques Le Goff (1991) Ilegó a sostener que el pasado "es una construcción y reinterpretación constante"; no en vano, definía a la disciplina histórica como "ciencia de un pasado reconstruido que se pone en cuestión continuamente" (pp. 28-29). En ese sentido, los historiadores pueden contribuir al análisis de las memorias entregadas de una generación a otra, como "especies universales", atemporales y acríticas, para esclarecer su formación, autoría, presupuestos teóricos, motivaciones, recursos, entre otros. Pero ello no solo es válido para defender el estatus epistémico de la Historia como ciencia. Hobsbawm (1998) afirmaba que ante el nacionalismo, entendido como un conjunto de mitos disfrazados de historia, lo que le queda a los historiadores es defender "el fundamento de su disciplina: la supremacía de los datos". Pues "la deconstrucción de mitos políticos o sociales disfrazados de historia forma parte desde hace tiempo de las obligaciones profesionales del historiador, con independencia de sus simpatías" (pp. 271-273). Es en última instancia, su "responsabilidad pública".

\section{Referencias}

- Allier Montaño, E. (2007). La (no) construcción de memorias sociales sobre el exilio político uruguayo. En E. Rey Tristán, (ed.), Memorias de la violencia en Uruguay y Argentina. Golpes, dictaduras, exilios (1973-2006). Santiago de Compostela: Universidad de Santiago de Compostela.

- Herrera Mena, S. (2014). Versiones y usos de la historia desde el Estado salvadoreño: a propósito del bicentenario (1811-2011). Revista de Historia $N^{\circ} 70$, p. 145. Universidad Nacional de Costa Rica.

- Hobsbawm, E. (1998). Sobre la historia. (pp. 271-273). Barcelona: Crítica.

- Juárez, J. (2011). Memoria e historia reciente en El Salvador. La necesidad de nuevos mitos en el presente salvadoreño. En E. Rey Tristán, y P. Cagiao (coord.), Conflicto, memoria y pasados traumáticos: El Salvador contemporáneo. (pp. 275-285). Santiago de Compostela: Universidad de Santiago de Compostela. 
- Le Goff J. (1991). Pensar la historia. Modernidad, presente y progreso, (pp. 28-29). Barcelona: Paidós.

- Sprenkels R. (2011). La memoria militante. Historia y política en la posguerra salvadoreña. En E. Rey Tristán, y P. Cagiao, (coord.), Conflicto, memoria y pasados traumáticos: El Salvador contemporáneo. (pp. 255-273). Santiago de Compostela: Universidad de Santiago de Compostela.

- Vattimo, G. (2003). Posmodernidad: ¿una sociedad transparente? En G. Vattimo. et al, En torno a la posmodernidad. (p. 10). Barcelona: Antrophos.

- Walter, K. (2005). La historia en El Salvador a comienzos del siglo XXI. En Memoria del Primer Encuentro de Historia de El Salvador, 22-25 de julio de 2003, (p. 20). San Salvador: CONCULTURA.

Notas

1 Conceptos tomados de Allier Montaño (2007).

2 Véanse los siguientes ensayos: Memoria e historia reciente en El Salvador. La necesidad de nuevos mitos en el presente salvadoreño, de Juárez (2011), y La memoria militante. Historia y politica en la posguerra salvadoreña, de Sprenkels (2011). 